\title{
CONSENSUS DATING OF MAMMOTH REMAINS FROM WRANGEL ISLAND
}

\author{
Kh. A. ARSLANOV, ${ }^{1}$ G. T. COOK, ${ }^{2}$ STEINAR GULLIKSEN, ${ }^{3}$ D. D. HARKNESS, ${ }^{4}$ \\ TUOVI KANKAINEN, ${ }^{5}$ E. M. SCOTT, ${ }^{6}$ SERGEY VARTANYAN ${ }^{7}$ and GANNA I. ZAITSEVA ${ }^{8}$
}

\begin{abstract}
Previous results from remains of tusks, teeth and bones collected from Wrangel Island (Vartanyan et al. 1995) had given results in the range $3730 \mathrm{BP}$ to $20,000 \mathrm{BP}$ and the authors had concluded that "mammoths inhabited Wrangel Island for as long as $6000 \mathrm{yr}$ after the estimated extinction on the Siberian continent". There still remained the question of the earliest date for such remains. Further, the authors had noted such samples may present some difficulty in dating and therefore duplicate samples had been measured in a second laboratory with satisfactory results. The replicate dating of important or controversial samples in more than one laboratory is well-established (e.g., Turin Shroud) and in this paper, we present results for 5 mammoth samples dated by 6 laboratories. Such interlaboratory comparisons provide an independent means of verification of laboratory comparability, and give added confidence in the results, particularly when applied to more controversial samples. A further objective of the work has been to evaluate the material for inclusion in any large-scale interlaboratory comparison, such comparisons having in the past formed part of laboratory quality assurance protocols. The design and organization of a laboratory intercomparison requires homogeneous samples in sufficient quantity to satisfy participants, and so in principle, a single mammoth tusk would meet these criteria. Samples such as the mammoth tusk have been used in previous intercomparisons: e.g., in the last large-scale international intercomparison (Gulliksen and Scott 1995), whalebone was one of the materials distributed. One of the key advantages of such material is that a single sample (a mammoth tusk) can be resampled for analysis by multiple labs and thus does not require bulk homogenization. Therefore, as part of a preselection process for a future intercomparison, five samples from separate mammoth tusks were collected from Wrangel Island in 1995 in sufficient quantity to allow multiple dating. The aim was to identify five separate samples of young age, sample up to $1 \mathrm{~kg}$ from each tusk and mark the location so that after preliminary dating, samples could be retrieved as required in the future. Six laboratories received samples for dating. The paper will discuss the results from the laboratories, present consensus values, and make recommendations concerning use of these samples in a future laboratory intercomparison.
\end{abstract}

\section{INTRODUCTION}

Wrangel Island is located on the border of the East Siberian and Chukchi Seas, separated from the mainland by Long Strait. As such, many of the mammoth samples found in the frozen ground or in river-bed sediments are well preserved. Dating of mammoth remains from Wrangel Island has resulted in improved knowledge concerning time scales on which the animals became extinct and so have contributed to an understanding of the causes of extinction.

The significance of the Wrangel Island samples relates to the young ages measured for some of the remains. It is hypothesized that mammoths on the mainland became extinct between 20 and $30 \mathrm{ka}$ ago but that in different locations, they may have survived till less than $13 \mathrm{ka}$ ago. However, the remains from Wrangel Island (Vartanyan et al. 1993, 1995) showed that mammoths survived even until the Holocene-considerably younger than any previously dated mammoth remains.

\section{Objectives of this Project}

The main aim of this project was the investigation of the suitability of the Wrangel island material for a further intercomparison for radiocarbon labs, during which the material could be formally characterized. Amongst the key properties such samples need to have are: well-identified prove-

\footnotetext{
${ }^{1}$ Geographical Research Institute, St. Petersburg State University, St. Petersburg, Russia

${ }^{2}$ Scottish Universities Research and Reactor Centre, Scottish Enterprise Technology Park, East Kilbride, Scotland

${ }^{3}$ Radiologisk Datering, NUST, N-7034 Trondheim, Norway

${ }^{4}$ NERC ${ }^{14} \mathrm{C}$ Lab, Scottish Enterprise Technology Park, East Kilbride, Scotland

${ }^{5}$ Geological Survey of Finland, Espoo, Finland

${ }^{6}$ Department of Statistics, University of Glasgow, Glasgow, Scotland

${ }^{7}$ Wrangel Island State Reserve, Magadan Region, Russia

${ }^{8}$ Institute of the History of Material Culture, St. Petersburg, Russia
} 
nance, availability of large amounts of material and crucially that the material should be homogeneous, as well as, of course, being of scientific interest. The mammoth samples of Wrangel Island, on the basis of a preliminary scrutiny, seemed to be suitable. The critical issue of sample homogeneity could be easily resolved by using material from a single tusk. Accessibility of the material is of course also important, and unfortunately Wrangel Island is both remote and inhospitable. Nevertheless, because of the interest in mammoths and their extinction at this location, it seemed of interest to 1) assess the material for use and 2) to further investigate the question of the earliest period when mammoths were still found.

\section{Sample Collection and Preparation}

The tusk samples used were cut from complete tusks belonging to the working collection of the State Reserve. One of the authors (SV) collected them from two river beds on Wrangel Island during fieldwork of 1991-1993. Bone material arrives at the river beds from friable sediments destroyed by the river. The friable sediments on Wrangel Island are not thick and there are no horizons containing large amounts of fossils. Thus, the most studied material comes from the resedimented material collected in the river beds and beaches. Five distinct mammoth tusks were selected: (24M-28M), 25M and $26 \mathrm{M}$ come from the same river bed (Gusinaya River), while 24M, 27M and 28M come from Tundrovaya River. It is possible that $25 \mathrm{M}$ and $26 \mathrm{M}$ come from a single animal, since they were found very close together and are of a similar size. $27 \mathrm{M}$ is also very interesting, since it was broken in the animal's lifetime and then the end of the tusk was polished through the activities of the animal. The tusks were all well preserved, indicating that they were only recently released from the permafrost (tusks on the surface are destroyed over several years). Single sections were cut from each tusk. The tusks were then marked and reburied so that they could be retrieved again at a future date. With the permission of the authorities, the material was then shipped to the United Kingdom, where the sections were cut into smaller samples and distributed to the participants.

A small number of labs (listed in Table 1) had previously been approached and asked if they would be willing to date up to 5 samples of mammoth tusk. The labs made use of liquid scintillation counting (LSC), gas proportional counting (GPC) and, in two cases (NTH and N/AMS), prepared targets and submitted them for measurement by accelerator mass spectrometry (AMS) (to the Uppsala and Arizona facilities, respectively). No instructions were given concerning methods of pretreatment. In most cases, however, collagen was extracted by acid-alkali extraction.

TABLE 1. List of Participants

\begin{tabular}{|c|c|c|}
\hline Name of lab and code & $\begin{array}{l}\text { Type of } \\
\text { analysis }\end{array}$ & Participants \\
\hline Radiologisk datering, Trondheim (NTH) & AMS & $\begin{array}{l}\text { Steinar Gulliksen } \\
\text { Gro Locke }\end{array}$ \\
\hline Geological Survey of Finland (GSF) & GPC & Tuovi Kankainen \\
\hline SURRC, East Kilbride (SURRC) & LSC & $\begin{array}{l}\text { Gordon Cook } \\
\text { Philip Naysmith }\end{array}$ \\
\hline Institute of History and Material Culture (IHM), St. Petersburg & LSC & Ganna Zaitseva \\
\hline Geography Institute, St Petersburg (GI) & LSC & Kh. A. Arslanov \\
\hline NERC, East Kilbride (NERC, N/AMS) & $\begin{array}{l}\text { LSC } \\
\text { \& AMS }\end{array}$ & $\begin{array}{l}\text { Doug Harkness } \\
\text { Charlotte Bryant }\end{array}$ \\
\hline
\end{tabular}




\section{RESULTS}

The results $\left({ }^{14} \mathrm{C}\right.$ age $\mathrm{BP} \pm 1 \sigma$ error and $\left.\delta^{13} \mathrm{C}\right)$ are given in Table 2. It was not possible for all labs to receive all five samples. Two labs were unable to make $\delta^{13} \mathrm{C}$ corrections and their preliminary results were submitted without correction. After the preliminary results had been circulated, both labs (indicated in the table) made corrections based on the reported $\delta^{13} \mathrm{C}$ results. The results for each sample are also plotted in Figure 1 in the form of a range, age $\pm 2 \sigma$. We can see that the results generally overlap.

TABLE 2. Results of Mammoth Dating

\begin{tabular}{|c|c|c|c|c|c|}
\hline \multirow[b]{2}{*}{ Lab name } & \multicolumn{5}{|c|}{ Sample code } \\
\hline & $24 \mathrm{M}$ & $25 \mathrm{M}$ & $26 \mathrm{M}$ & $27 \mathrm{M}$ & $28 \mathrm{M}$ \\
\hline $\begin{array}{l}\mathrm{NTH} \\
\delta^{13} \mathrm{C}\end{array}$ & $\begin{array}{c}6225 \pm 80 \\
-22.7 \\
\end{array}$ & $\begin{array}{c}6720 \pm 110 \\
-21.9\end{array}$ & & $\begin{array}{c}4570 \pm 55 \\
-22.4\end{array}$ & $\begin{array}{c}7580 \pm 60^{*} \\
-22.2 \\
\end{array}$ \\
\hline $\begin{array}{l}\text { GSF } \\
\delta^{13} \mathrm{C} \\
\end{array}$ & $\begin{array}{c}6155 \pm 40 \\
-22.7 \\
\end{array}$ & $\begin{array}{c}6660 \pm 30 \\
-22.0 \\
\end{array}$ & $\begin{array}{c}6545 \pm 30 \\
-22.1 \\
\end{array}$ & & $\begin{array}{c}7450 \pm 30 \\
-22.4 \\
\end{array}$ \\
\hline $\begin{array}{l}\text { SURRC } \\
\delta^{13} \mathrm{C}\end{array}$ & $\begin{array}{c}6110 \pm 90 \\
-23.4\end{array}$ & $\begin{array}{c}6640 \pm 70 \\
-24.9\end{array}$ & $\begin{array}{c}6620 \pm 50 \\
-22.3 \\
\end{array}$ & $\begin{array}{c}4340 \pm 50 \\
-23.2 \\
\end{array}$ & \\
\hline IHM† & $6110 \pm 40$ & $6360 \pm 40$ & $6650 \pm 50$ & $\begin{array}{c}3630 \pm 70 \\
4530 \pm 70 \ddagger \\
\end{array}$ & $\begin{array}{c}6700 \pm 70 \\
7460 \pm 70 \ddagger \\
\end{array}$ \\
\hline $\begin{array}{l}\text { NERC1 } \\
\delta^{13} \mathrm{C} \\
\end{array}$ & & $\begin{array}{c}6625 \pm 40 \\
-22.5 \\
\end{array}$ & $\begin{array}{c}6355 \pm 45 \\
-21.9 \\
\end{array}$ & $\begin{array}{c}4445 \pm 45 \\
-22.3 \\
\end{array}$ & $\begin{array}{c}7380 \pm 45 \\
-23.1 \\
\end{array}$ \\
\hline $\begin{array}{l}\text { N/AMS } \\
\delta^{13} \mathrm{C}\end{array}$ & $\begin{array}{c}6250 \pm 60 \\
-22.3 \\
\end{array}$ & $\begin{array}{c}6660 \pm 55 \\
-22.1\end{array}$ & $\begin{array}{c}6725 \pm 55 \\
-22.0\end{array}$ & $\begin{array}{c}4445 \pm 50 \\
-21.9\end{array}$ & $\begin{array}{c}7450 \pm 65 \\
-22.5\end{array}$ \\
\hline $\mathrm{GI}^{\dagger}$ & $6100 \pm 70$ & $6640 \pm 70$ & $6430 \pm 70$ & $4570 \pm 80$ & $7340 \pm 120$ \\
\hline
\end{tabular}

*Redated result for $28 \mathrm{M}$

†Corrected for $8^{13} \mathrm{C}$, using values reported in table

$¥$ After correction for residual activity in benzene used for sample dilution

One of the advantages for participating laboratories is the identification of any potential problems. Several were indeed identified. One lab identified a problem with the benzene used for sample dilution (residual activity), and submitted a set of corrected results (marked by $\ddagger$ in the table) resulting in corrections of $800-1000 \mathrm{yr}$ in two samples. A single anomalous result for $28 \mathrm{M}$ was also identified; this result was obtained by AMS and the lab had previously noted that there had been a reduction in ion current for this sample. At the same time, in-house quality assurance checks showed a problem. A redating of the material (from the same collagen extraction) gave a result $1000 \mathrm{yr}$ younger. Further investigation of the reason for this anomalous result is underway, but these two comments indicate some of the advantages provided by the opportunity to cross-check results. This demonstrates that participation in such programs provides information on laboratory performance not otherwise obtainable. Summary statistics for each sample are shown in Table 3. The results for this suite of samples again confirm that the mammoth remains of Wrangel Island are among the youngest known, dating to the mid-Holocene. The $\delta^{13} \mathrm{C}$ results confirm the terrestrial origin of the samples. 


\section{Statistical Analysis of the Results}

The remaining section is concerned with the statistical analysis of results from interlaboratory comparisons. Such analysis can be used to answer questions of interest; for example, what is the level of agreement between labs? Do they agree on average, or is there any relative bias, and also to investigate the variation in the results? The summary statistics in Table 3 show that the range of results for each sample spans several hundreds of years and in most cases, the standard deviation of the results is greater than the quoted errors. Finally, the coefficient of variation in Table 3, which indicates the variation in results relative to the age, varies by a factor of 2 over the samples; $25 \mathrm{M}, 26 \mathrm{M}$ and $27 \mathrm{M}$ show more variation relative to their mean age than $24 \mathrm{M}$ and $28 \mathrm{M}$. Graphical analysis can also prove useful in this context and there are a number of possible graphical representations.

Figure 2 shows the deviations from the average value for each sample. The extent and location of the points relative to zero line shows the scale of variation in results. Such a plot makes it easier to assess the magnitude of disagreement (both in terms of precision and bias). Such a diagram may also be used to assess if the difference in results is related to the age of the samples. From Figure 2, it is clear that there are differences in results, which might indicate the existence of small, relative biases.

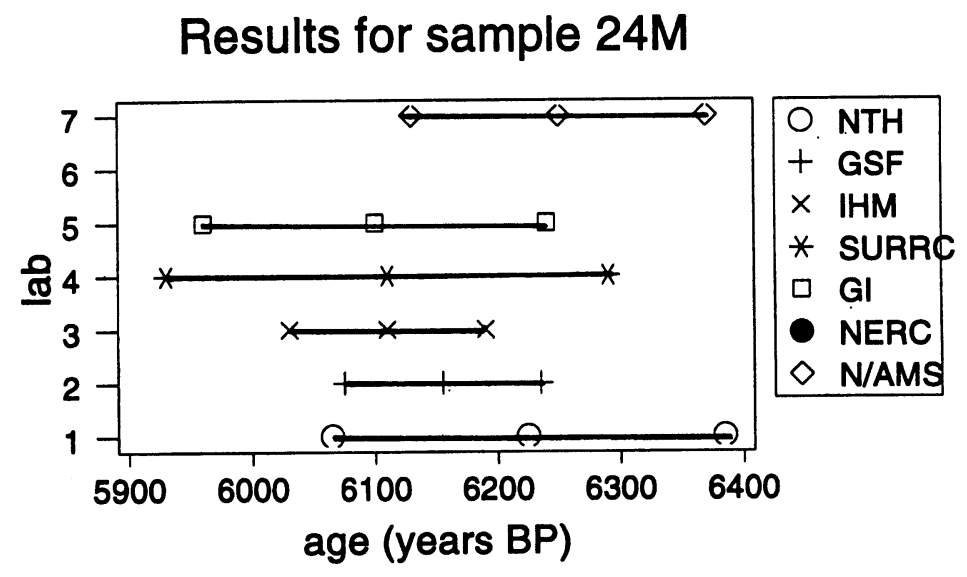

Results for sample $25 \mathrm{M}$

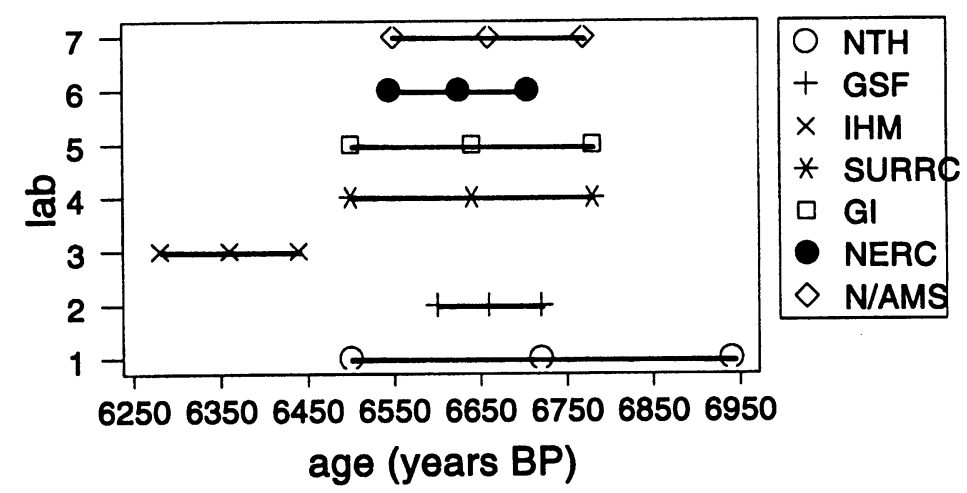

Fig. 1. (Above and facing page). Results for mammoth samples showing age \pm 2 quoted uncertainties 
Results for sample 26M

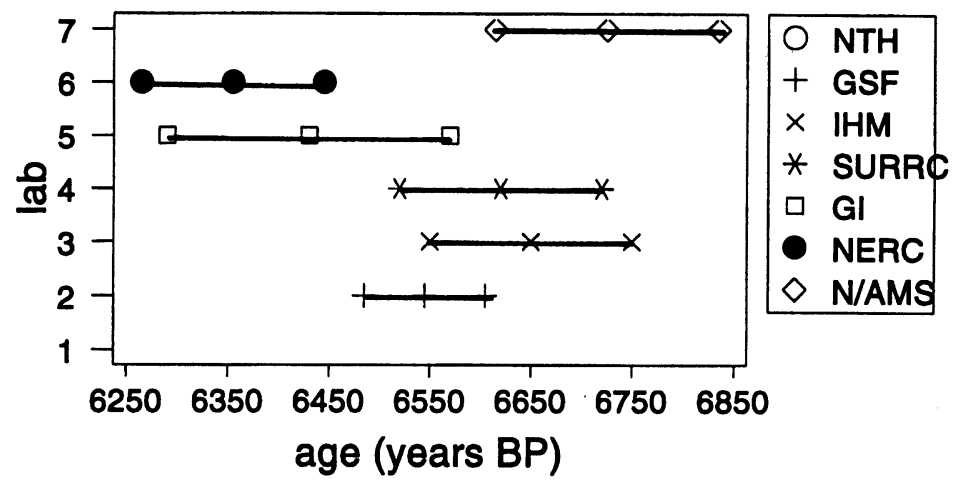

Results for sample 27M

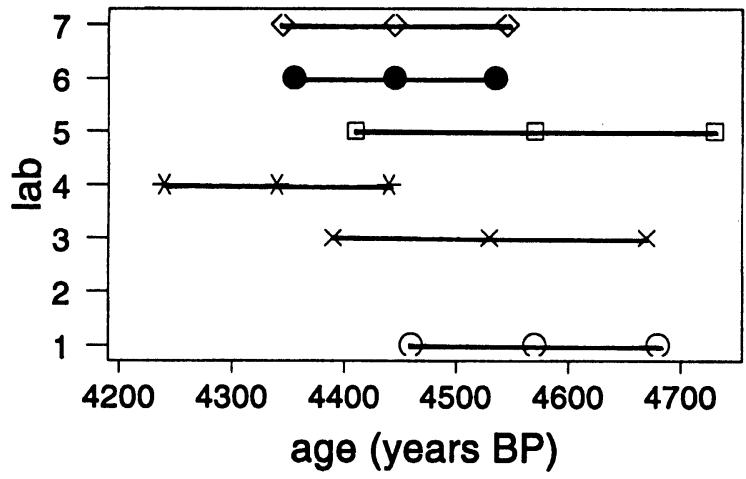

O NTH

+ GSF

$\times$ IHM

* SURRC

$\square$ GI

- NERC

$\diamond$ N/AMS

Results for $28 \mathrm{M}$

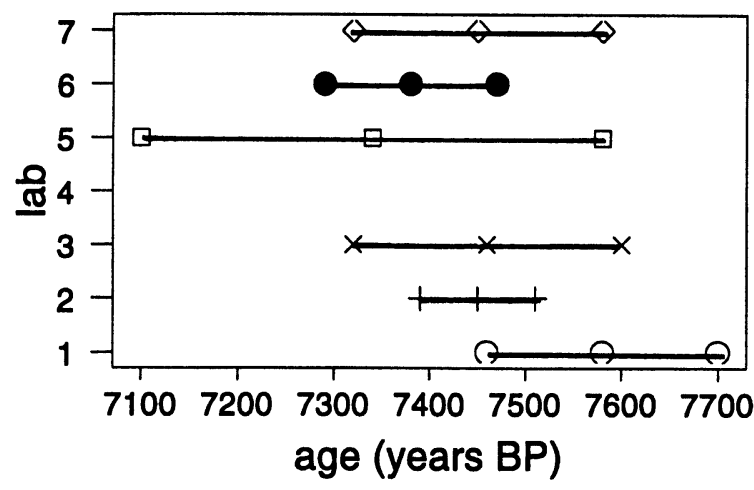

\begin{tabular}{|ll|}
\hline$O$ & NTH \\
+ & GSF \\
$\times$ & IHM \\
$*$ & SURRC \\
$\square$ & GI \\
0 & NERC \\
$\diamond$ & N/AMS \\
\hline
\end{tabular} 
TABLE 3. Summary Statistics

\begin{tabular}{llllll}
\hline Sample code & $24 \mathrm{M}$ & $25 \mathrm{M}$ & $26 \mathrm{M}$ & $27 \mathrm{M}$ & $28 \mathrm{M}$ \\
Average & 6158 & 6615 & 6554 & 4483 & 7443 \\
Median & 6132 & 6640 & 6582 & 4487 & 7450 \\
Standard deviation & 64.7 & 116.5 & 139.9 & 90.2 & 82.1 \\
Range & 125 & 360 & 370 & 230 & 210 \\
Coefficient of variation & 1.05 & 1.76 & 2.13 & 2.01 & 1.01 \\
\hline
\end{tabular}

*Coefficient of variation evaluated as (standard deviation/mean) $\times 100$

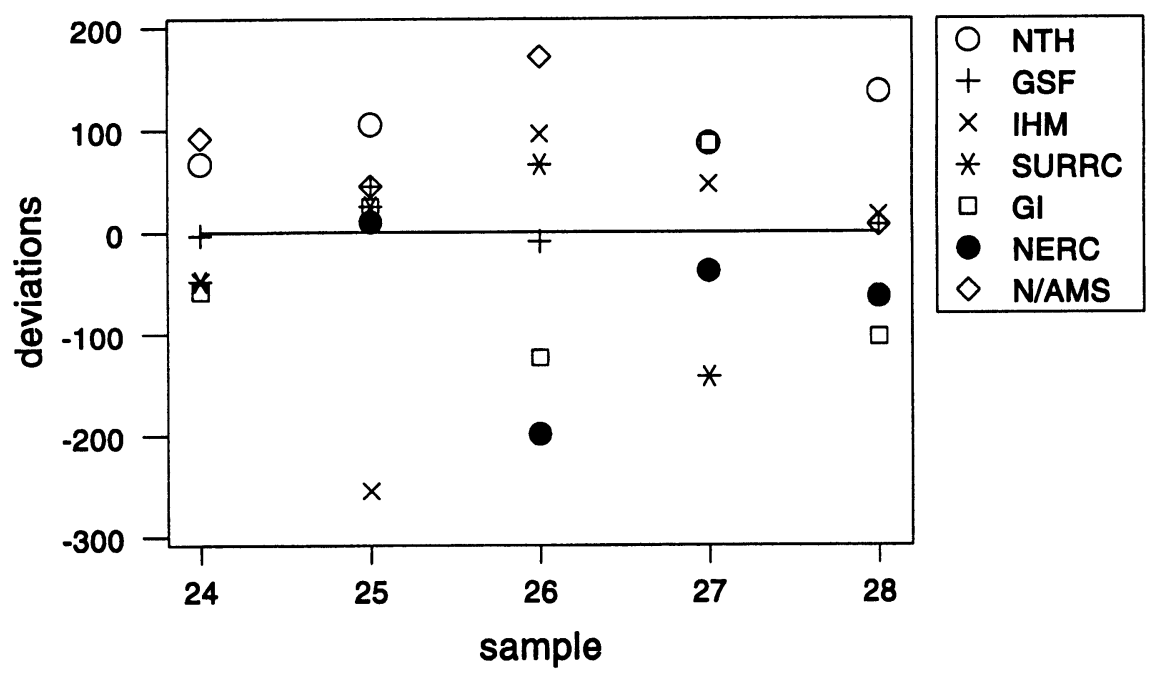

Fig. 2. Scatterplot showing deviation of results from mean ages

\section{CoNCLUSION}

The results from the five mammoth tusk samples from Wrangel Island show that mammoths lived on the island during the Holocene (the youngest specimen has a ${ }^{14} \mathrm{C}$ date of $c a .4490 \mathrm{BP}$ ). Individual samples show some differences among the labs, and there is evidence of relative biases, explanations for which are being sought by the labs. The variation in the results (up to several hundred years) is larger than might be predicted given the use of single tusks but may reflect differences in standards, any natural variation in the material, and pretreatment effects, as had been identified in previous intercomparisons (Scott, Long and Kra 1990). Further samples will be sought for use in a large-scale intercomparison.

\section{REFERENCES}

Gulliksen, S. and Scott, E. M. 1995 Report of the TIRI workshop. In Cook, G. T., Harkness, D. D., Miller, B. F. and Scott, E. M., eds., Proceedings of the 15th International ${ }^{14} \mathrm{C}$ Conference. Radiocarbon 37(2): 820-822.

Scott, E. M., Long, A. and Kra, R. S., eds. 1990 Proceedings of the International Workshop on Intercomparison of ${ }^{14} \mathrm{C}$ Laboratories. Radiocarbon 32(3): 253-397.

Vartanyan, S. L., Arslanov, Kh. A., Tertychnaya, T. V. and Chernov, S. B. 1995 Radiocarbon dating evidence for mammoths on Wrangel Island, Arctic Ocean, until 2000 BC. Radiocarbon 37(1): 1-6.

Vartanyan, S. L., Garutt, V. E. and Sher, A. V. 1993 Holocene dwarf mammoths from Wrangel Island in the Siberian Arctic. Nature 362: 337-340. 